\title{
Is nitrogen accumulation in grain legumes responsive to growth or ontogeny?
}

\author{
Hélène Marrou ${ }^{a}$, Jaumer J. Ricaurte ${ }^{b}$, Michel E. Ghanemc, José A. Clavijo Michelangelid, Lamiae \\ Ghaoutie, Idupulapati M. Rao ${ }^{\mathrm{b}}$ and Thomas R. Sinclair ${ }^{\mathrm{d}^{*}}$ (C) \\ aMontpellier SupAgro, UMR SYSTEM, 34060, Montpellier, France \\ bInternational Center for Tropical Agriculture (CIAT), Cali, Colombia \\ ${ }^{c}$ Crop Physiology Laboratory, International Center for Agricultural Research in the Dryland Areas (ICARDA), Rabat, Morocco \\ ${ }^{d}$ Crop and Soil Sciences Department, North Carolina State University (NCSU), Raleigh, NC, USA \\ eInstitut Agronomique Vétérinaire (IAV), Rabat, Morocco
}

\section{Correspondence \\ *Corresponding author, \\ e-mail: trsincla@ncsu.edu}

Received 29 July 2017

doi:10.1111/ppl.12617

\begin{abstract}
Nitrogen $(\mathrm{N})$ accumulation in legumes is one of the main determinants of crop yield. Although $\mathrm{N}$ accumulation from symbiotic nitrogen fixation or $\mathrm{N}$ absorption from the soil has been widely investigated, there is no clear consensus on timing of the beginning of $\mathrm{N}$ accumulation and the termination of $\mathrm{N}$ accumulation and the physiological events that may be associated with these two events. The analyses conducted in this study aimed at identifying the determinant of $\mathrm{N}$ accumulation in two grain legume species. Nitrogen accumulation dynamics and mass accumulation and development stages were recorded in the field for several genotypes of common bean (Phaseolus vulgaris) and faba bean (Vicia faba) under different growing conditions. This study showed that during the vegetative stages, $\mathrm{N}$ accumulation rate was correlated with mass accumulation rate. However, the maximum accumulation of $\mathrm{N}$ did not correspond to the time of the maximum mass accumulation. In fact, for both species, $\mathrm{N}$ accumulation was found to persist in seed growth. This challenges a common hypothesis that seed growth causes a decrease in $\mathrm{N}$ accumulation because of a shift of the photosynthate supply to support the seed growth. Even more surprising was the shift of the active accumulation of $\mathrm{N}$ in faba bean to late in the growing season as compared with common bean. $\mathrm{N}$ accumulation by faba bean only was initiated at high rates very late in vegetative growth and persisted at high rates well into seed fill.
\end{abstract}

\section{Introduction}

Nitrogen $(\mathrm{N})$ is widely recognized, together with water, as the most crucial resources to promote the crop yield increase (Sinclair and deWit 1975, Godwin and Jones 1991, Soltani and Sinclair 2012). However, an intensive use of mineral fertilizer to increase the $\mathrm{N}$ availability of crops during the green revolution has resulted in concern for environmental issues, such as groundwater pollution, eutrophication of aquatic ecosystems and increase in greenhouse gas emissions (Tilman et al. 2002, IPCC 2007). As a consequence, the need for a better understanding of the physiological determinants of $\mathrm{N}$ capture and use by plants has been growing over the past decades. Legumes are of particular interest because they have the capacity to accumulate $\mathrm{N}$ in two

Abbreviations - AIC, Akaïke criterion; CTUs, cumulative temperature units; DAS, days after sowing; DW, dry weight; GR, growth rate; Ir, irrigated; NIr, non-irrigated; tBNA, time of beginning of nitrogen accumulation; tBSG, time of beginning of seed growth; tTNA, time of termination of N accumulation; tTSG, time of termination of seed growth. 
different interactive processes: symbiotic $\mathrm{N}_{2}$ fixation from the atmosphere and $\mathrm{N}$ uptake from the soil.

Nitrogen accumulation in crops has been extensively studied (Cooper et al. 1976, Smith et al. 1988, Ney et al. 1997, Jamieson and Semenov 2000, Lemaire et al. 2007) using various approaches. However, studies exploring source-sink relations in cereals, for example, have generated inconsistent results to explain the $\mathrm{N}$ uptake and allocation within plants (Dreccer et al. 1997, Rajcan and Tollenaar 1999, Martre et al. 2003). Fewer studies have been conducted with legumes, and even more confusion seems to remain because of the involvement of $\mathrm{N}$ accumulation from the soil and symbiotic $\mathrm{N}_{2}$ fixation. Nevertheless, it is generally assumed that $\mathrm{N}$ accumulation is correlated with crop mass growth causing $\mathrm{N}$ concentration in the different organs to remain equal to or less than a target concentration (Coleman et al. 1993, Boote and Hoogenboom 1998, Robertson et al. 2002, Martre et al. 2003). However, a few studies also indicate that $\mathrm{N}$ accumulation in aerial mass during vegetative growth can be better related to leaf area expansion because stem may serve as a temporary storage pool to support leaf expansion (Jamieson and Semenov 2000, Sinclair et al. 2003). In addition, the nature and size of sinks for $\mathrm{N}$ are often related to ontogeny, and $\mathrm{N}$ accumulation dynamics are commonly related to developmental stages (Cooper et al. 1976, Ney et al. 1997, Voisin and Gastal 2015).

Uncertainty and confusion remain specifically about the time during the growing season of beginning of $\mathrm{N}$ accumulation, the termination of $\mathrm{N}$ accumulation (tTNA) and the intervening rate of $\mathrm{N}$ accumulation. The timing of the beginning of $\mathrm{N}$ accumulation and the switch from germinating seed reserve to alternative sources of $\mathrm{N}$ are poorly documented. Also, proposals for the tTNA range from the beginning of the seed-filling stage to some time during seed fill. To complicate matters, during seed fill, $N$ is generally translocated from leaves and stems to reproductive organs to support the grain growth. Several authors reported that the total $\mathrm{N}$ accumulation in aboveground dry matter plateaus at the beginning of seed growth as the high demand for carbohydrates by the seeds may result in little or no carbohydrate to support the additional $\mathrm{N}$ accumulation (Lawlor 2002, Voisin et al. 2002, Soltani and Sinclair 2012). However, contradictory results have been reported in cowpea (Vigna unguiculata) and black gram (Vigna mungo) (Sinclair et al. 1987). In faba bean (Vicia faba), Herdina and Silsbury (1990) showed that half of the plant $\mathrm{N}$ is accumulated after the beginning of seed growth, although $\mathrm{N}_{2}$ fixation starts decreasing at the onset of the seed-filling phase. Their results also indicated large discrepancies in the $\mathrm{N}$ accumulation dynamics between faba bean and field pea (Pisum sativum).
Overall, few experiments have provided insight into the actual ontogenetic events associated with $\mathrm{N}$ accumulation in grain legumes by either $\mathrm{N}$ absorption from the soil or $\mathrm{N}_{2}$ fixation. There are at least two reasons for this failure. First, the limitation in $\mathrm{N}$ uptake is known to affect the plant growth through a close interaction with other limiting resources, mainly water, in a complex relationship (Devries et al. 1989, Thomas et al. 2004, Quemada and Gabriel 2016). Second, differences in the dynamics of $\mathrm{N}$ accumulation and remobilization during grain fill have been shown among both cool-season species (Herdina and Silsbury 1990) and tropical species (Devries et al. 1989, Muchow et al. 1993). However, these species comparative studies have all been based on the assessment of one genotype per species and did not offer results for direct comparison between cool-season and tropical species. There is no published study comparing the dynamics of $\mathrm{N}$ accumulation among grain legume species that included several genotypes.

The objective of this study was to analyze the temporal dynamics of $\mathrm{N}$ accumulation of two grain legume species: common bean (Phaseolus vulgaris), a warm-season species, and faba bean, a cool-season species. These two species were selected to represent the diversity in $\mathrm{N}_{2}$-fixing capacity and area of production. Field experiments were conducted to document the $\mathrm{N}$ dynamics throughout a growing season of several genotypes within each species. An important part of this objective was an attempt to correlate ontogenic events with the temporal dynamics of $\mathrm{N}$ accumulation and the total plant $\mathrm{N}$ content. The influence of high temperature and drought was considered in the common bean and faba bean experiments.

\section{Materials and methods}

\section{Experimental sites and plant material}

\section{Common bean}

Experiments on common bean were conducted at two sites in southwestern Colombia: Palmira, Valle del Cauca (PAL, $965 \mathrm{~m}$ a.s.I.); Darien, Valle del Cauca (DAR, 1570 $\mathrm{m}$ a.s.l.). The soil at PAL was a mollisol and at DAR it was an inceptisol. The soil at PAL was high in phosphorus and the soil at DAR low in phosphorus. The altitude difference between the two locations resulted in environmental differences. At low-altitude PAL, the maximum average temperature was $31^{\circ} \mathrm{C}$, and the daily mean radiation was $14.2 \mathrm{MJ} \mathrm{m}^{-2} \mathrm{~d}^{-1}$ during the experimental time period. At high-altitude DAR, the maximum average temperature was $25.5^{\circ} \mathrm{C}$ and the daily mean radiation was 18.6 MJ m $\mathrm{m}^{-2} \mathrm{~d}^{-1}$. Thus, the PAL site can be considered 
as a suboptimal growing situation compared with DAR because of the lower daily incoming radiation at PAL. Also, the higher temperature at PAL resulted in a shorter growing season than that at DAR.

Six genotypes (CAL 96, ICA Quimbaya, DOR 364, SER 118, G 21212 and Carioca) were grown. These genotypes were chosen to represent two major gene pools (Andean: CAL 96 and ICA Quimbaya; and Mesoamerican: DOR 364, SER 118, G 21212 and Carioca). Also, these genotypes included three widely grown growth habits (I: CAL 96 and ICA Quimbaya; II: DOR 364 and SER 118; III: G 21212 and Carioca).

The plots were sown on October 3, 2013, at PAL and May 29, 2014, at DAR as part of the study on the effects of planting density on common bean growth and development (Ricaurte et al. 2016). Split plots in a fully randomized design was used at both sites with three replicates at DAR and four replicates at PAL, respectively. Experimental units were $4 \mathrm{~m}$ long with seven-row plots at DAR and eight-row plots at PAL, respectively. The row spacing was $0.6 \mathrm{~m}$, and the results for the 25 -plants $\mathrm{m}^{-2}$ density are presented here. Non-limiting conditions were maintained throughout the growth cycle by applying $60 \mathrm{~kg} \mathrm{Pha}^{-1}$ at sowing at DAR. At both sites, there was application of, micronutrients by foliar sprays and irrigation to avoid water-deficit stress. No $\mathrm{N}$ fertilization was applied, but seeds were inoculated with Rhizobium tropici CIAT 899.

\section{Faba bean}

The faba bean experiment was conducted at the Institut Agronomique et Vétérinaire Hassan II, in Rabat, northern Morocco. The soil at this location was a low-fertility sandy luvisol. Four genotypes (Féverole de Fès, Aguadulce, and two breeding lines of the Agricultural Center for Agricultural Research in the Dry Areas (ICARDA): HBP/SOF/2009 and HBP/SO/06-L4301-4/09) were included in the study to represent two seed size types (broad bean: Aguadulce, HBP/SOF/2009; small seeds: Féverole de Fès, HBP/SO/06-L4301-4/09). Also, these genotypes represented two intensities of breeding: local traditional genotypes (Féverole de Fès, Aguadulce) and newly bred lines (HBP/SOF/2009, HBP/SO/06-L4301-4/09).

Prior to the experiment, mustard (Sinapis alba) was grown as green manure. The field was fertilized with diamonophosphate $\left(100 \mathrm{~kg} \mathrm{ha}^{-1}\right)$ before sowing and ammonitrate $\left(30 \mathrm{~kg} \mathrm{ha}^{-1}\right)$ on March 18, 2015, around flowering date. Weeding and aphid control were performed to avoid biotic stress in both treatments.

The experiment was sown on December 2, 2014, in a split-plot design with three replicates. Experimental units were $3 \mathrm{~m}$ long with four-row plots spaced at $0.6 \mathrm{~m}$. The experiment included two watering treatments: irrigated (Ir) and non-irrigated (NIr) treatments. Irrigation treatment was the main plot, and genotypes were the subplots. Ir treatment was started on March 6, 2015, shortly before anthesis. Cumulative rainfall from the sowing to beginning of irrigation was $284 \mathrm{~mm}$. Because cumulative ET0 was only $95 \mathrm{~mm}$ by this time, all plots were well watered up to anthesis. Cumulative rainfall after March 6 was only $80 \mathrm{~mm}$, most of which was received before the end of March, resulting in drought for the NIr treatment. In the Ir treatment, irrigation was applied at intervals of $1-3$ days so that greater than $300 \mathrm{~mm}$ was applied. This irrigation was sufficient to fully meet faba bean water use from anthesis to harvest under Mediterranean conditions (Siddique et al. 2001, Maalouf et al. 2015).

\section{Measurements}

Plants in both experiments were observed at least weekly to determine the $50 \%$ flowering stage (R1), beginning of seed growth (BSG - the date when $50 \%$ of plants had 1-cm-long pods) and physiological maturity, which was assumed equivalent to the termination of seed growth.

Crop growth was monitored through destructive sampling. For common bean, sampling was performed at DAR every week from 22 days after sowing (DAS) for a total of eight sampling dates and at PAL from 14 DAS for a total of six sampling dates. At each sampling date, all plants in a $30 \mathrm{~cm}$ length of row from two central rows of each plot were collected (around seven plants). The plant components were divided into leaves, stems and, if pods existed, the podwalls and seeds were separated. The samples were dried in an oven for $48 \mathrm{~h}$ at $60{ }^{\circ} \mathrm{C}$.

For faba bean, samples were also collected every 2 weeks, from 80 DAS to the termination of seed growth in both water treatments (six sampling dates for Ir and five sampling dates for NIr). At each sampling date, 25 $\mathrm{cm}$ length was collected from each of the four rows of a plot. Samples were then separated by organ, dried in an oven at $60^{\circ} \mathrm{C}$ for 4 days and weighed.

All dried samples were analyzed for $\mathrm{N}$ concentration of each organ, and the total N content per plant (NTOTgpp, g plant ${ }^{-1}$ ) at each sampling date was calculated as follows:

$$
\text { NTOTgpp }=\sum_{\text {organ } \in\left\{\begin{array}{c}
\text { leaves, stems, } \\
\text { podwalls, seeds }
\end{array}\right\}}\left(\mathrm{DW}_{\text {organ }} \times[\mathrm{N}]_{\text {organ }}\right)
$$


where $\mathrm{DW}_{\text {organ }}$ is the dry mass of organ $\left(\mathrm{g} \mathrm{plant}^{-1}\right)$ and $[N]_{\text {organ }}$ is the $\mathrm{N}$ concentration in the corresponding organ $\left(\mathrm{g} \mathrm{N} \mathrm{g}^{-1}\right)$.

Sampling date and date of occurrence of ontogenetic stages were recorded as DAS. These data were converted into cumulative temperature units $\left(\mathrm{CTUs},{ }^{\circ} \mathrm{C}\right)$, using a three-segment function to describe the growth rate response to temperature as described by Soltani and Sinclair (2012). For common bean, base temperature, optimal temperature and critical temperature were set, respectively, to 10,24 and $30^{\circ} \mathrm{C}$ (Marrou et al. 2014). For faba bean, the base temperature was set to $0^{\circ} \mathrm{C}$ (Boote et al. 2002), and the optimal and critical temperatures were assumed to be greater than the maximum average temperature experienced during the experiment $\left(26^{\circ} \mathrm{C}\right)$.

\section{Ontogenetic events}

The visual observations of time of beginning of seed growth (tBSG) and time of termination of seed growth (tTSG) were not fully consistent with the estimates of tBSG and tTSG based on the harvested seed weights. Therefore, updated estimates of ontogenetic stages were computed based on the logistic regression model between seed weight and CTU. Estimates of tBSG were defined as the CTU when seed weight reached $5 \%$ the final asymptote value and of tTSG were defined as the CTU when seed weight reached $95 \%$ of the asymptote value. (The comparison of these estimations of tBSG and TTSG with the visual field notations are given in Appendix 1).

\section{Growth rate (GR) dynamics}

Because mass accumulation has been hypothesized as a possible driver for initiation and termination of $\mathrm{N}$ accumulation, the growth rate (GR) was calculated throughout the growth cycle. Estimation of GR can be calculated using two different contrasting approaches. The classical approach consists of calculating the difference in dry matter accumulation per plant between two measurement dates, divided by the time elapsed between the two measurements. The value calculated can be considered as an estimate of the GR at a date approximately in the middle between the two measurement dates. This approach has the advantage of using directly observed values for computation, but the approach is destructive, so different plants are sampled at each measurement resulting in potentially high variability.

The second approach is based on estimating GR continuously from regression of sample mass against time throughout the whole cropping season. In these regressions, the fit was done between the total dry weight per plant (DW) and CTU because CTU was a better descriptor of progress in plant development and growth than date. The following logistic function was fitted for each genotype $(g)$ and each site or treatment $(t)$.

$$
\mathrm{DW}_{g, t}(\mathrm{CTU})=\frac{A_{g, t}}{1+\mathrm{e}^{\left(-\frac{\mathrm{CTU}-m_{g, t}}{s_{g, t}}\right)}}
$$

where $\mathrm{DW}_{g, t}(\mathrm{CTU})$ is the total dry weight per plant at $\mathrm{CTU}$, for genotype $g$ and treatment $t ; A_{g, t}, m_{g, t}$ and $s_{g, t}$ are the regression parameters of the logistic function. The asymptote, $A_{g, t}$, was an output from the regression for common bean. However, for faba bean, the last sample was taken shortly after physiological maturity, so these data were used to define $A_{g, t}$ based on the maximum dry weight per plant, averaged over repetitions per treatment and genotype.

GR was computed continuously as the derivative of Eqn 2 (Radford 1967, Poorter and Gamier 1996, Hoffmann and Poorter 2002). By definition, the maximum GR was reached when CTU equaled $m_{g, t}$ and stopped at $\left(A_{v, t} /\left(4^{*} s_{v, t}\right)\right)$. A caution has been noted that in these estimates of GR, a limited number of repetitions may not allow a good statistical fit to the data, which could result in anomalous estimations of GR (Poorter 1989, Hunt 2003).

\section{Temporal dynamic of $\mathbf{N}$ accumulation}

Similar to the total dry weight per plant, the temporal dynamic of the total plant $\mathrm{N}$ content was represented using a logistic model fitted between the total $\mathrm{N}$ content (NTOT, g plant ${ }^{-1}$ ) and time from sowing, expressed in CTU. As given in Eqn 3, NTOT $_{g, t}(\mathrm{CTU})$ is the total $\mathrm{N}$ content in the plants $\left(\mathrm{g}\right.$ plant ${ }^{-1}$ ) for genotype $g$, in treatment or site $t$ at CTU, and $A_{N, g, t}, m_{N, g, t}$ and $S_{N, g, t}$ are the parameters of the logistic function for each variety and site.

$$
\mathrm{NTOT}_{g, t}(\mathrm{CTU})=\frac{A_{N, g, t}}{1+\mathrm{e}^{\left(-\frac{\mathrm{CTU}-m_{N, g, t}}{s_{N, g, t}}\right)}}
$$

For faba bean as for common bean, $A_{N, g, t}$ was set equal to the maximum $\mathrm{N}$ content (averaged over repetitions) observed for each variety and treatment. For common bean, data for the final harvest were discarded to fit the logistic adjustment because dry leaves were not collected at that date.

The logistic model (Eqn 3) was first adjusted without any effect on the parameters of the logistic function 
Table 1. Dates of flowering (tR1, observed in field) tBSG, tTSG, tBNA and tTNA, expressed in CTU of faba bean and common bean genotypes growing under different treatments (I, irrigated; NI, non-irrigated) and at different sites (DAR, Darien; PAL, Palmira). Calculations of tBSG, tTSG, tBNA and tTNA are based on the logistic regression of biomass or the total nitrogen accumulation against thermal time.

\begin{tabular}{|c|c|c|c|c|c|c|c|}
\hline Species & Treatment & Genotype & tR1 & tBSG & tTSG & tBNA & tTNA \\
\hline \multirow[t]{8}{*}{ Faba bean } & \multirow[t]{4}{*}{ I } & Fev de fes & 1183 & 1550 & 2159 & 1000 & 2202 \\
\hline & & Aguadulce & 1305 & 1518 & 2075 & 999 & 2119 \\
\hline & & HBP/SOF/2009 & 1183 & 1503 & 2373 & 1180 & 2291 \\
\hline & & HBP/SO/06-L4301-4/09 & 1183 & 1330 & 2353 & 924 & 2222 \\
\hline & \multirow[t]{4}{*}{$\mathrm{NI}$} & Fev de fes & 1183 & 1366 & 1954 & 766 & 1975 \\
\hline & & Aguadulce & 1267 & 1558 & 1839 & 1319 & 1630 \\
\hline & & HBP/SOF/2009 & 1267 & 1492 & 1897 & 1237 & 1730 \\
\hline & & HBP/SO/06-L4301-4/09 & 1183 & 1396 & 1906 & 1181 & 1756 \\
\hline \multirow[t]{12}{*}{ Common bean } & \multirow[t]{6}{*}{ DAR } & CAL 96 & 511 & 663 & 1079 & 105 & 863 \\
\hline & & Carioca & 578 & 746 & 914 & 179 & 968 \\
\hline & & DOR 364 & 562 & 653 & 1094 & 69 & 1000 \\
\hline & & G 21212 & 530 & 706 & 846 & 78 & 909 \\
\hline & & ICA Quimbaya & 500 & 750 & 862 & 70 & 918 \\
\hline & & SER 118 & 535 & 554 & 1109 & 159 & 763 \\
\hline & \multirow[t]{6}{*}{ PAL } & CAL 96 & 428 & 528 & 714 & 248 & 751 \\
\hline & & Carioca & 483 & 605 & 837 & 264 & 822 \\
\hline & & DOR 364 & 486 & 686 & 809 & 299 & 805 \\
\hline & & G 21212 & 453 & 556 & 796 & 261 & 821 \\
\hline & & ICA Quimbaya & 422 & 497 & 961 & 323 & 718 \\
\hline & & SER 118 & 455 & 546 & 914 & 322 & 817 \\
\hline
\end{tabular}

(simple model), then with treatment effect and, eventually, with a genotype effect within each site or treatment, on each parameter of the logistic equation (complete model). The CTUs for the beginning of nitrogen accumulation (tBNA) and tTNA were estimated for each variety and treatment or site as the CTU when the total nitrogen content reached, respectively, 5 and $95 \%$ of the asymptote for each genotype and each treatment.

\section{Statistical tools and methods}

All non-linear adjustments were carried out with the $\mathrm{R}$ software (https://cran.r-project.org/) using the nls and gnls functions of package nlme. The comparison of the dynamics of $\mathrm{N}$ accumulation between sites, genotypes and growing conditions was made using nested model comparison based on the Akaïke information criterion (AIC). The estimated values of parameters for logistic models of the total dry mass and total $\mathrm{N}$ accumulation are presented in Appendix 2. Effect of sites, growing conditions and genotypes on the total mass or $\mathrm{N}$ accumulation at the final harvest were tested by the analysis of variance (ANOVA) models using the Im and aov functions in $\mathrm{R}$ software. Genotype was considered as a nested effect within the site or irrigation treatment effect to comply with the experimental design. Mean comparisons were done using Tukey's HSD test.

\section{Results}

\section{Ontogeny}

Mass accumulation data were used to estimate the seed development stage as described previously. The tBSG estimated from the logistic regression was always estimated to occur after visual flowering by an average of 125 CTUs in common bean and 245 CTUs in faba bean (Table 1). The relative root mean square error between estimated ontogenetic stages based on the seed growth and visually observed ontogenetic stages was only $7 \%$ (see Appendix 1). Thus, estimations of tBSG and tTSG based on the logistic regression on seed growth were considered as reliable. Under stresses of high-temperature (common bean) or water-deficit (faba bean) conditions, crop cycle was significantly shortened, with tBSG and tTSG occurring earlier.

\section{Mass accumulation}

In the case of common bean, the total accumulated mass was approximately equal $(P$-value $=0.07)$ between the PAL site (12.2 $\mathrm{g} \mathrm{plant}^{-1}$ ) and the DAR site (14.5 $\mathrm{g} \mathrm{plant}^{-1}$ ) with similar values among genotypes within each site $(P$-value $=0.13)$. The entire dynamic of mass accumulation modeled by Eqn 2 was found to differ between sites when comparing models using AIC (Fig. 1). Mass accumulation did not differ among genotypes in DAR, while 
A

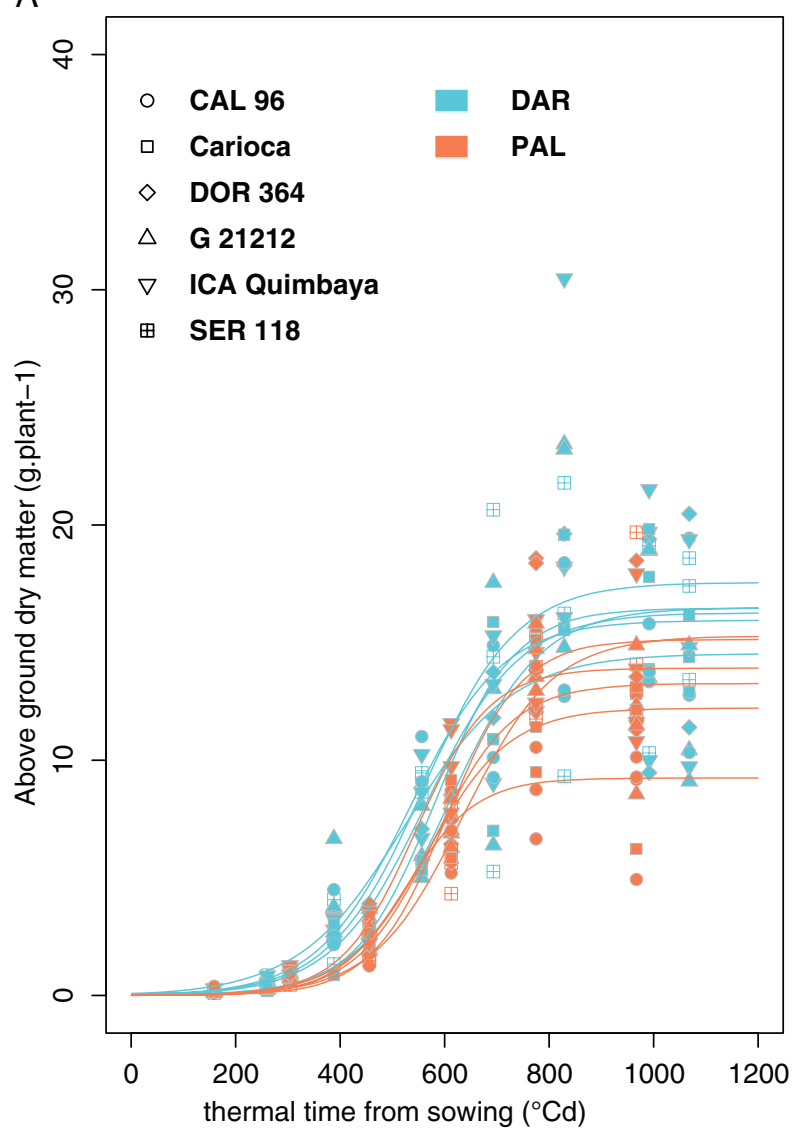

B

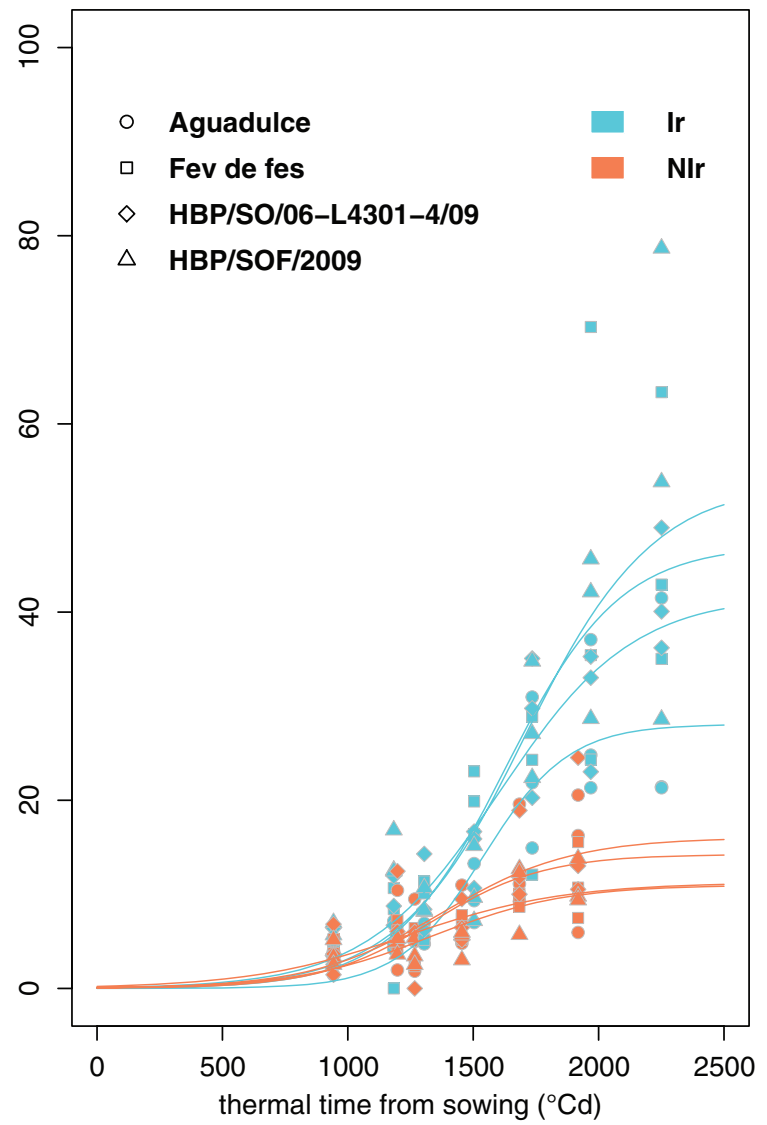

Fig. 1. Observed (closed symbols) dry weight per plant ( $\mathrm{g} \mathrm{plant}^{-1}$ ) and predicted values of dry weight (solid lines) using the logistic model (Eqn 2) from sowing (CTU) for common bean (A) and faba bean (B) growing at different sites (DAR, Darien; PAL, Palmira) and under different treatments (I, irrigated; NI, non-irrigated).

under non-optimal conditions at the PAL site, significant differences in the dynamic of mass accumulation were detected among genotypes.

In the case of faba bean, the total mass at the final harvest was reduced significantly $(P$-value $=0.0018)$ under $\operatorname{NIr}\left(13.1\right.$ g plant $\left.^{-1}\right)$ as compared with $\operatorname{Ir}\left(42.7\right.$ g plant $\left.^{-1}\right)$. However, no significant differences in final dry weight were found among genotypes within the same watering treatment $(P$-value $=0.67)$ (Fig. 1$)$. For each site, model comparison using AIC showed that all genotypes grown at the same site could be modeled with a common set of parameters in Eqn 3.

GR was calculated using both the difference approach and the derivative approach. For common bean at PAL, GR was very similar between the two approaches (root mean square of error (RMSE) between the two approaches ranged between 0.0039 and $0.0068 \mathrm{~g}$ plant $^{-1} \mathrm{CTU}^{-1}$ ) (Fig. 2). This similarity in estimating GR by the two approaches was not found at DAR for common bean and for faba bean in both watering treatments.
The difference approach for calculating GR was found inappropriate as it resulted in unrealistic values with time for some genotypes.

GR as calculated from the derivative of the mass accumulation regression followed a symmetrical dynamic: GR increased until maximum and then declined until maturity. For common bean, the maximum GR was approximately $0.05 \mathrm{~g} \mathrm{plant}^{-1} \mathrm{CTU}^{-1}$ at the two sites; however, the time when this maximum was reached differed (Fig. 2). The maximum GR was achieved around flowering at the DAR site. At the PAL site, where development was accelerated because of high temperature and low radiation likely limiting photosynthesis, the maximum GR was not reached until between flowering and the beginning of seed growth.

In the case of faba bean (Fig. 3), the maximum GR of the NIr treatment was much lower (approximately $0.015 \mathrm{~g} \mathrm{plant}^{-1} \mathrm{CTU}^{-1}$ ) than that of the Ir treatment (approximately $0.055 \mathrm{~g} \mathrm{plant}^{-1} \mathrm{CTU}^{-1}$ ). In the case of Ir 

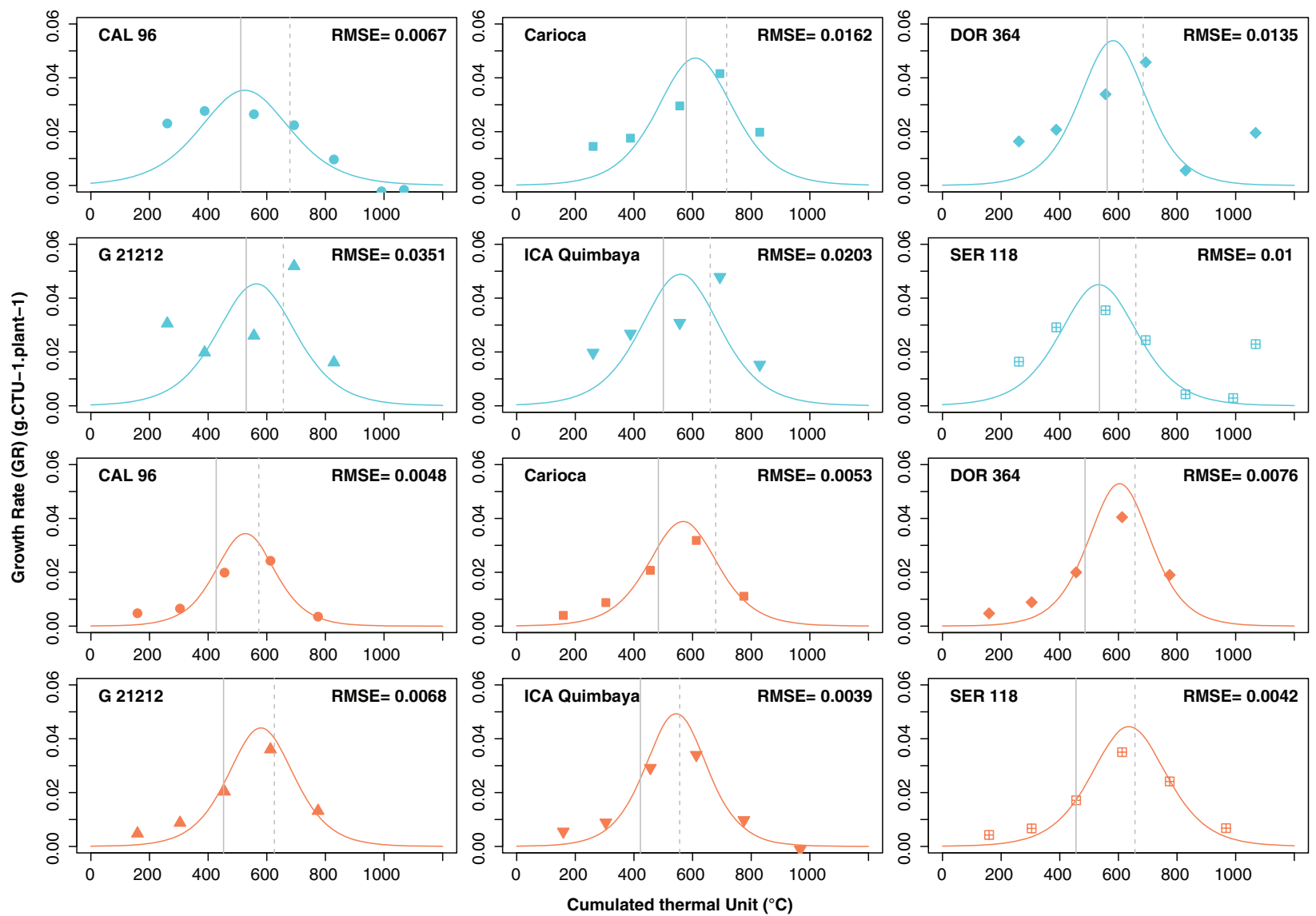

Fig. 2. GR as a function of CTU for common bean genotypes, as estimated by the difference approach (closed symbols) and the derivative approach (solid line) at the DAR site (turquoise) and at the PAL site (orange). The solid vertical line represents flowering time, while the dashed vertical line represents the beginning of seed growth.

faba bean, the maximum GR was achieved during the seed-filling phase. In contrast, GR did not increase after flowering for NIr faba bean.

\section{Nitrogen accumulation}

$\mathrm{N}$ accumulation could be successfully modeled in all cases using Eqn 3, and regression parameters were significantly different between sites for common bean and between watering treatments for faba bean, based on the comparison of AIC of nested models (Fig. 4). In particular, NTOT at the final harvest was affected in different ways by the climate and crop management. For common bean, there was no significant difference between the two experimental sites $(P$-value $=0.18)$. For faba bean, NTOT in the Ir treatment (1.32 g N plant ${ }^{-1}$ on average) was significantly greater than that in the $\mathrm{N} / r$ treatment $\left(0.40 \mathrm{~g} \mathrm{~N}\right.$ plant $\left.^{-1}\right)$ $(P$-value $=0.003)$.

Nitrogen accumulation under optimal growth conditions was initiated at different times in the growth cycle depending on the species. For common bean, $\mathrm{N}$ accumulation started (tBNA) at 69 to 179 CTUs at PAL and 248 to 322 CTUs at DAR, which occurred soon after germination in both cases (Table 1). In contrast, tBNA for faba bean was delayed to an average of 1026 CTUs or only about 200 CTUs before flowering (Table 1). The comparison of the estimates of tBNA from optimal conditions with non-optimal conditions also showed significant differences. There was a delay in tBNA for both stress conditions of higher temperature for common bean at the PAL site and of NIr treatment for faba bean (Table 1).

tTNA was highly correlated with tBSG in common bean $\left(R^{2}=0.63\right)$ and with tTSG in faba bean $\left(R^{2}=0.87\right)$ (Fig. 5). However, the CTUs for these stages were offset with tTNA occurring by an average of 222 CTUs after tBSG in common bean and 525 CTUs after tBSG in faba bean. Based on the ANOVA, TTNA was found to be significantly earlier when plants were stressed $(P$-value $<0.001$ for common bean and $P$-value $=0.025$ 

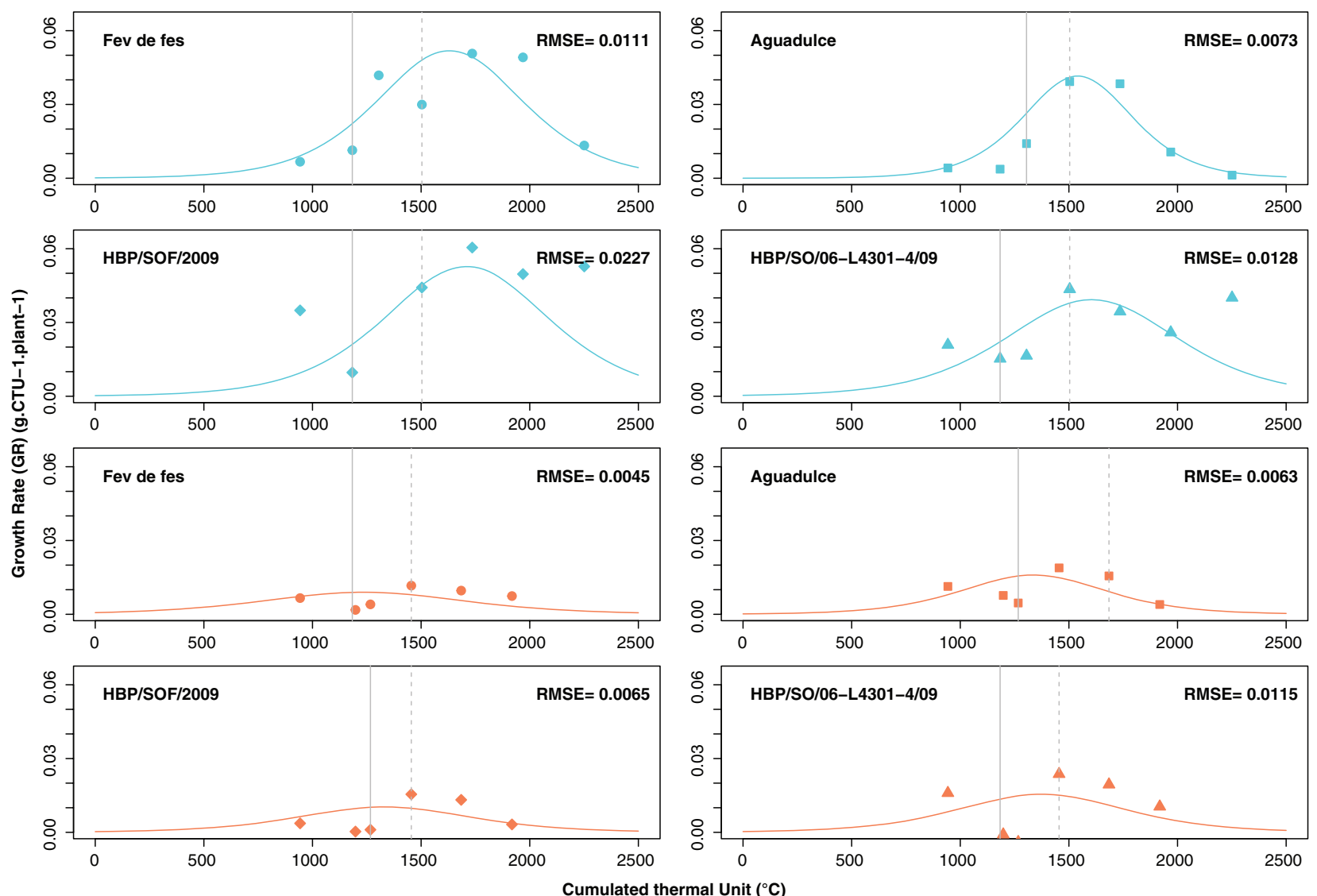

Fig. 3. GR as a function of CTU for faba bean genotypes, as estimated by the difference approach (closed symbols) and the derivative approach (solid line) for irrigated (turquoise) and non-irrigated conditions (orange). The solid vertical line represents flowering, while the dashed vertical line represents the beginning of seed growth.

for faba bean) with tTNA occurring shortly before tTSG by 64 CTUs in common bean and by 80 CTUs in faba bean.

No significant differences in final NTOT were found among genotypes within the same site or treatment, neither in common bean $(P$-value $=0.37)$, nor in faba bean $(P$-value $=0.62)$. Yet, common bean and faba bean genotypes used in these experiments were selected to cover a wide range of morphologies, seed size and gene pools. Comparing the $\mathrm{N}$ accumulation dynamics, significant differences were found among genotypes only for common bean at the PAL site and for Ir faba bean. Thus, genetic variability may exist in the dynamic of $\mathrm{N}$ accumulation, but it was detected only when differences among genotypes were large compared with the variability in measurements.

$\mathrm{N}$ allocation to organs was found to respond significantly to growing conditions only during the seed-filling phase (data not shown). The comparison of the proportion of $\mathrm{N}$ content located in leaves, stem and grain at a given date during seed filling showed that under non-optimal conditions (PAL site and NIr treatment), a higher proportion of $\mathrm{N}$ content was located in the seeds, while leaves would contain a lower proportion of $\mathrm{N}$ compared with plants grown under optimal conditions (DAR site and Ir treatment). It appeared that non-optimal conditions accelerated the translocation of $\mathrm{N}$ from leaves to seeds, while $\mathrm{N}$ dynamic in stems remains unaffected. No difference was found in the allocation of $\mathrm{N}$ between leaves and stems before flowering, neither between sites or treatments, nor genotype, for both species.

\section{Discussion}

The objective of this study was to compare the temporal dynamics of $\mathrm{N}$ accumulation by several genotypes of two grain legumes. The approach was to examine experimental results using a logistic function to analyze the accumulated plant mass and accumulated $\mathrm{N}$ 
A

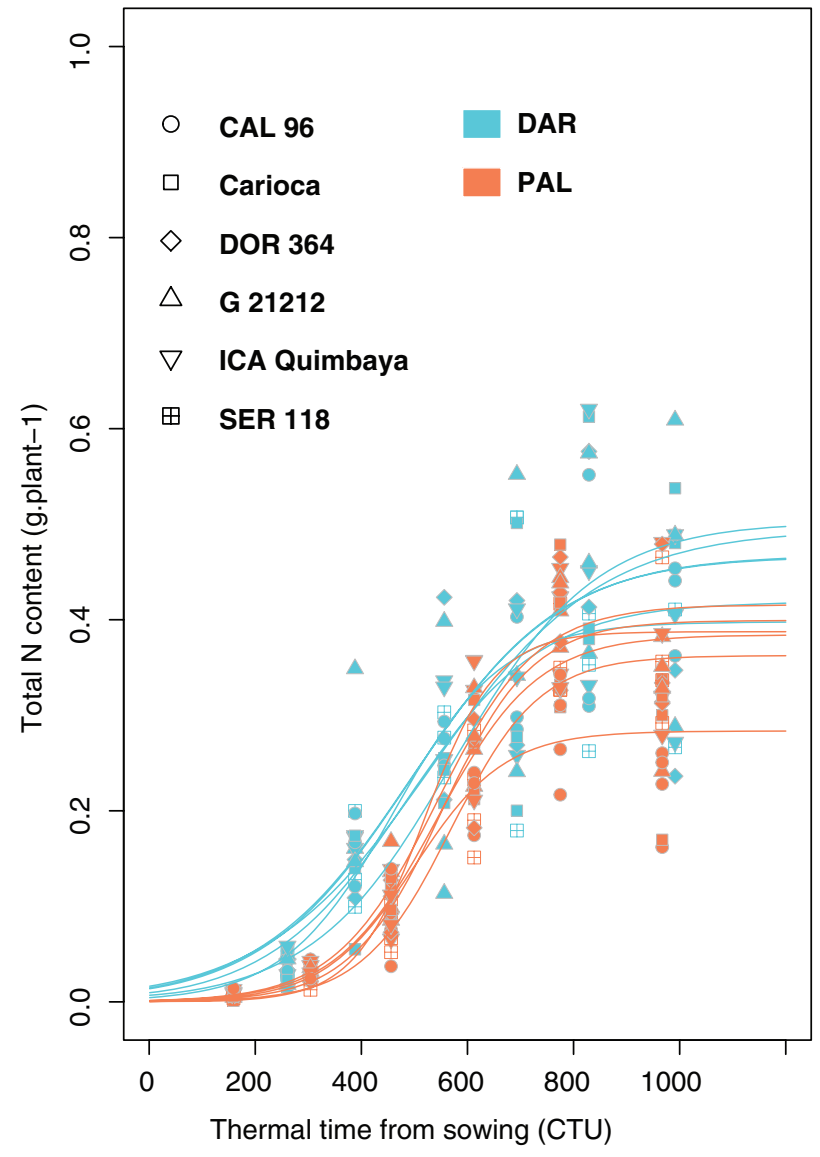

B

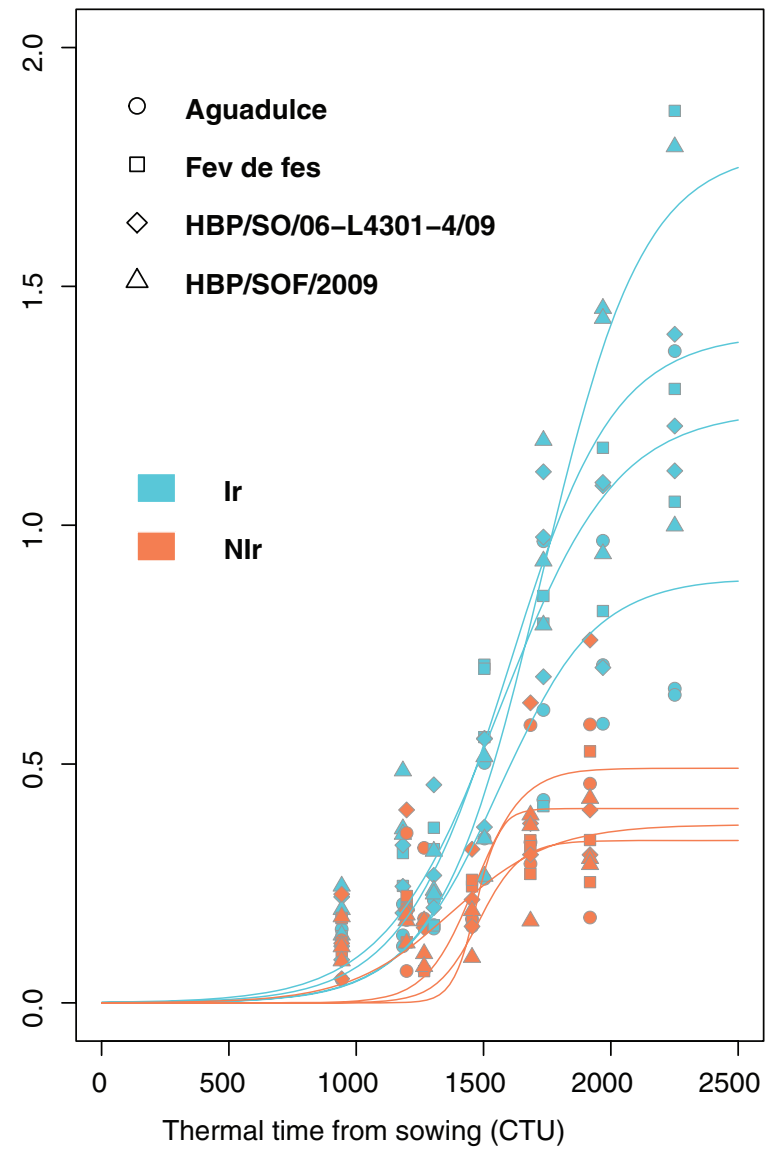

Fig. 4. Observed (closed symbols) nitrogen accumulation ( $\mathrm{g}$ plant ${ }^{-1}$ ) and predicted values of $\mathrm{N}$ accumulation (solid lines) using the logistic model (Eqn 3) as a function of CTU for (A) common bean grown at DAR and PAL and (B) faba bean grown under Ir and NIr water treatments.

throughout the cropping season. The results of the regression showed that the functions (Eqns 2 and 3) were appropriate in representing the change in mass and $\mathrm{N}$ with CTU (Fig. 1).

The analysis of the results expressed by the logistic equation allowed insight into the beginning and termination of $\mathrm{N}$ accumulation in these grain legumes. This study clearly showed that the timing of $\mathrm{N}$ accumulation in common bean and faba bean was quite different. While tBNA in common bean occurred shortly after germination and tTNA occurred on an average of 222 CTUs after tBSG, in faba bean, tBNA was not initiated until nearly flowering and sustained $\mathrm{N}$ accumulation well into seed fill (525 CTUs after tBSG). These results for faba bean are consistent with the results of Herdina and Silsbury (1990) with glasshouse-grown plants in which $\mathrm{N}$ accumulation began at flowering and more than half of the accumulation occurred during seed fill. The apparently unique delayed $\mathrm{N}$ accumulation pattern in faba bean seems especially deserving of further physiological investigation to understand its unexpected ability to sustain $\mathrm{N}$ accumulation in competition with seed growth.

During vegetative development, it has been hypothesized by various authors (Jamieson and Semenov 2000, Lawlor 2002, Sinclair et al. 2003, Lemaire et al. 2007) that $\mathrm{N}$ accumulation is sink-driven and closely related to leaf expansion and mass accumulation. The data from these experiments were used to examine this relationship by plotting NTOT (g N plant ${ }^{-1}$ ) and GR (g CTU ${ }^{-1}$ plant $^{-1}$ ) against each other. However, before doing this analysis, an initial consideration is that because NTOT experimentally includes plant mass in its determination, there may be a linkage between NTOT and GR, which is consistent with the mathematical linkage between GR and NTOT (derivative of Eqns 2 and 3).

In all experimental situations, the same parametric equations could be fitted for GR and NTOT although 
A

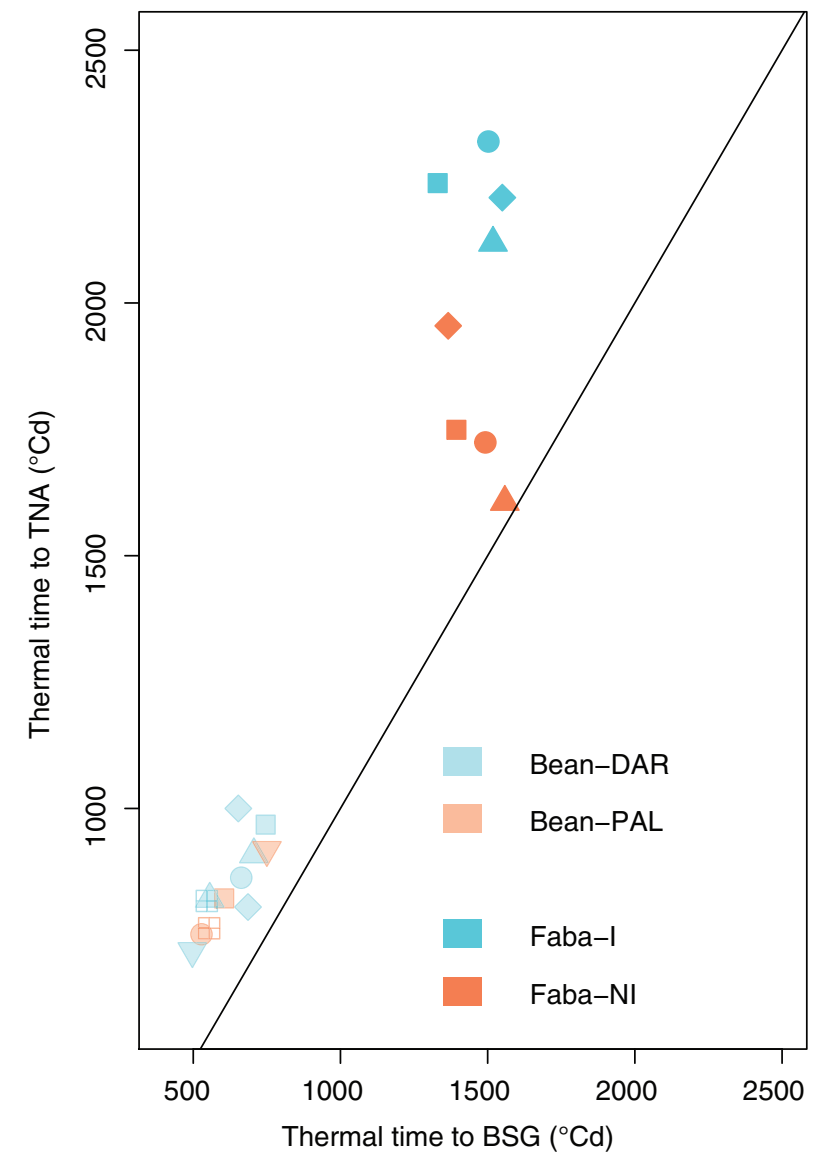

B

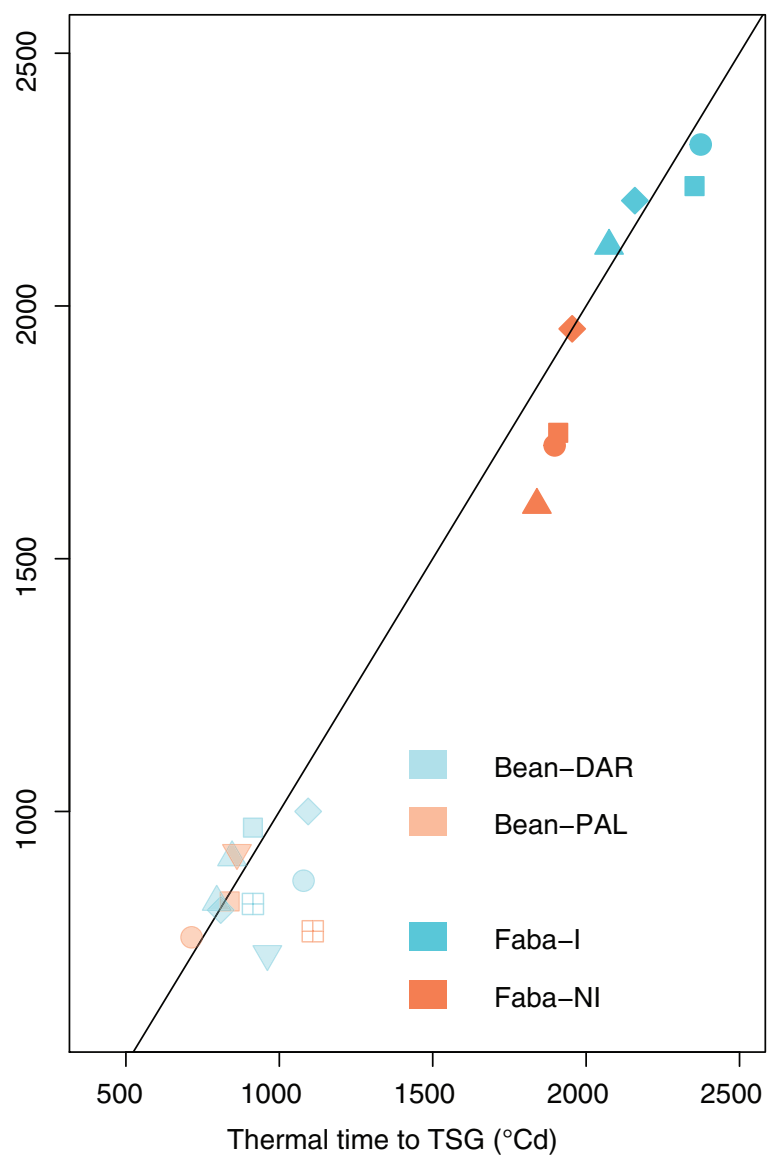

Fig. 5. Plot of CTU at tTNA vs (A) CTU at tBSG and (B) CTU at tTSG. The solid line represents the 1:1 correspondence.

parameters varied across species, genotypes and growing conditions. The sharp acceleration of NTOT increase vs GR appears when parameters $s_{N g, t}$ and $m_{N g, t}($ Eqn 3$)$ are, respectively, lower than $s_{g, t}$ and $m_{g, t}$ (Eqn 2). That is, $\mathrm{N}$ accumulation dynamic is much delayed and NTOT starts increasing steadily only after the maximum GR. These results indicate that there is no threshold in GR that triggers the beginning of $\mathrm{N}$ accumulation, unless dry matter is accumulating at a very slow rate because of unfavorable conditions.

The differences in GR and NTOT increases resulted in different patterns when GR and NTOT were plotted against each other (Figs 6 and 7). Generally, during the stages before flowering, there was approximately a linear relationship between GR and NTOT increases until reaching the maximum GR. Following the maximum GR, NTOT continued to increase, while GR decreased to zero. In the case of common bean, the relation between NTOT and GR was approximately linear in the two halves of the cycle.
In the case of NIr faba bean in which the crop was exposed to quite severe stress (P-PET $<250 \mathrm{~mm}$ ), the relation between GR and NTOT followed a somewhat different pattern for the other cases (Fig. 7). First, there appeared to be a threshold in GR of about $0.015 \mathrm{~g}$ plant $^{-1} \mathrm{CTU}^{-1}$ before NTOT increase was initiated. NTOT remained nearly constant at the beginning of the cycle, and then, $\mathrm{N}$ accumulation showed a sharp acceleration when GR became maximum $\left(0.01 \mathrm{~g} \mathrm{plant}^{-1}\right.$ $\mathrm{CTU}^{-1}$ to $0.02 \mathrm{~g} \mathrm{plant}^{-1} \mathrm{CTU}^{-1}$, depending on the genotype).

\section{Concluding remarks}

It is often suggested that $\mathrm{N}$ accumulation by crops is demand-driven and thus directly linked to dry matter accumulation (Imsande and Touraine 1994, Hammer et al. 2010, Bertheloot et al. 2011). Thus, $\mathrm{N}$ accumulation from the environment - either from the soil or from the atmosphere for grain legumes - is anticipated to be closely tied to sink size or sink growth rate. While 
A
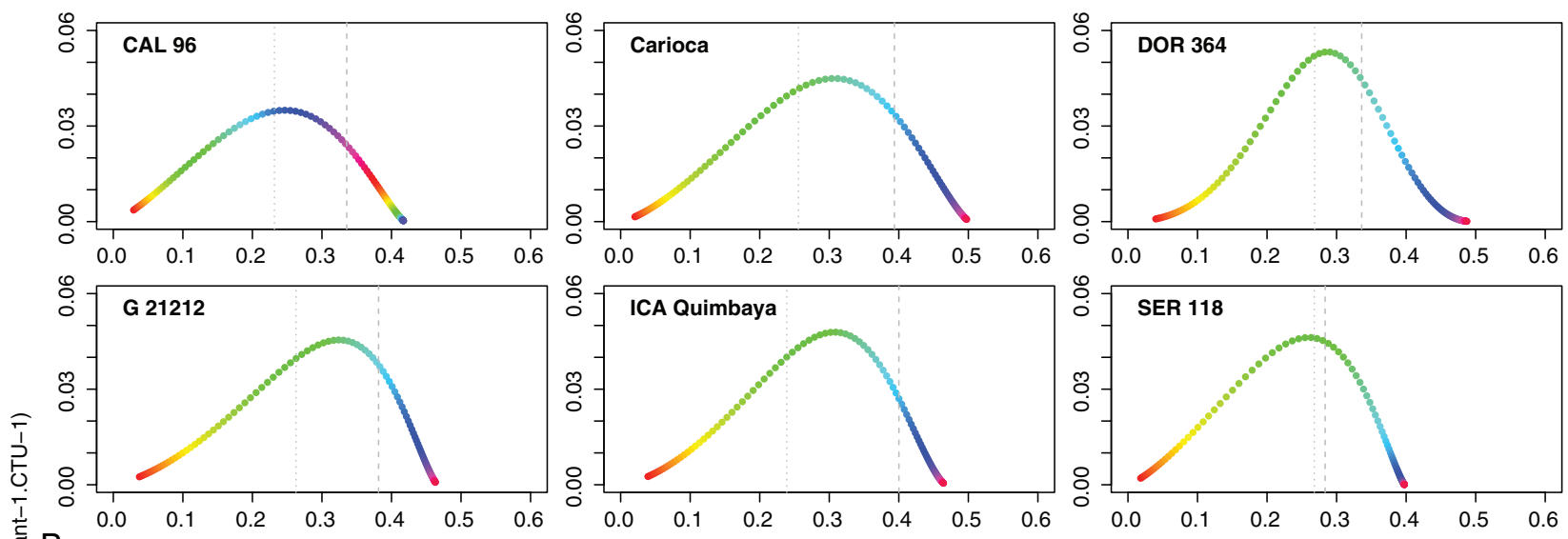

$\frac{\pi}{0} \mathrm{~B}$
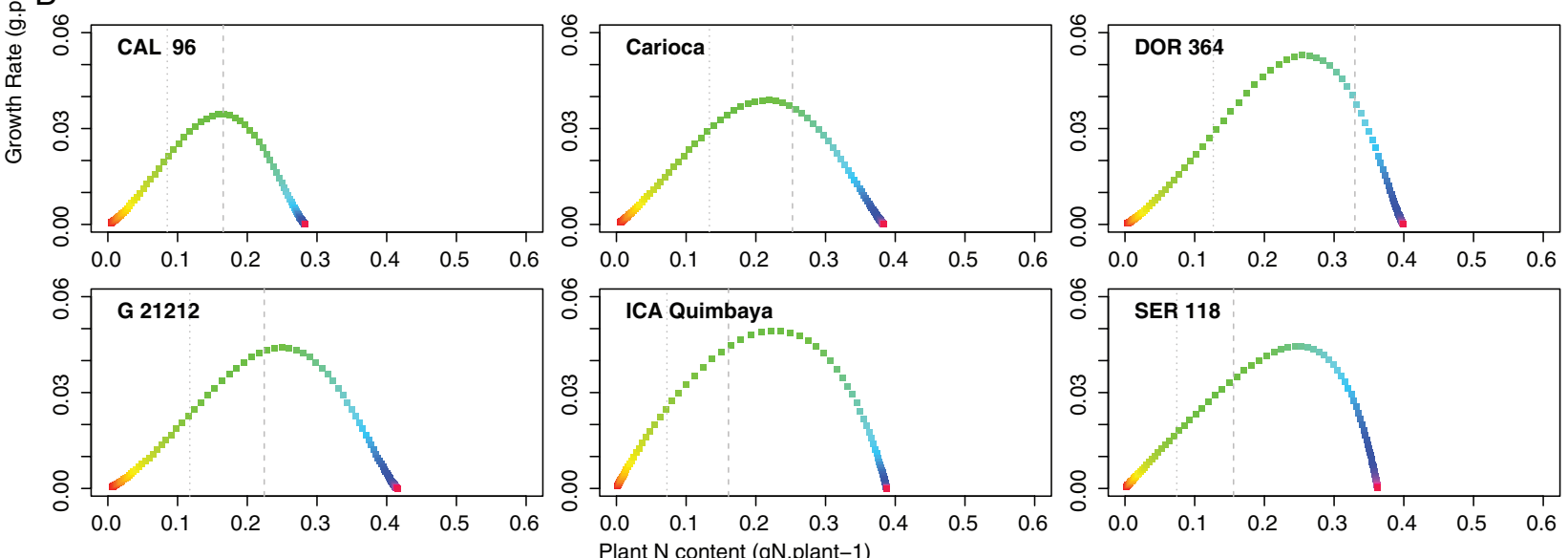

$\mathbf{0}$

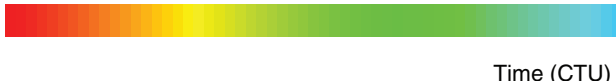

1200

Fig. 6. GR vs $N$ accumulation rate (NAR) for common bean at (A) the DAR site and (B) the PAL site. These rates are based on the derivatives of the logistic models fitted to observed total dry weights and the total $\mathrm{N}$ content. Point colors refer to time from sowing: The red-yellow points correspond to the beginning of cycle, while the blue-purple points correspond to the end of the cycle. The dotted vertical line is flowering time, while the dashed vertical line is the beginning of seed growth.

previous studies, e.g. Lemaire et al. (2007), showed that $\mathrm{N}$ accumulation and mass accumulation were correlated, in this study, the comparison of accumulation was pushed one step further by calculating and comparing accumulation rates. These results provided strong evidence in both the cool-season and dry-season legumes that while initially $\mathrm{N}$ accumulation is closely tied to mass accumulation, $\mathrm{N}$ accumulation continued well into the reproductive cycle. The large fraction of $\mathrm{N}$ accumulation during seed fill by faba bean is especially contradictory to the widely accepted hypothesis that the photosynthate competition stops $\mathrm{N}$ accumulation soon after seed-filling phase has started (Amir and Sinclair 1991, Hammer et al. 2010). Previous experimental studies on non-legume crops also support this result:
Ruiter and Brooking (1996) showed that in barley, substantial amounts of $\mathrm{N}$ can be acquired by crops during seed-filling phase. Our findings bring additional evidence about the variability that exists in $\mathrm{N}$ accumulation in legumes during both vegetative and reproductive phases and their representation in mechanistic crop models.

Acknowledgements - The authors thank the CGIAR CRP Grain Legumes for funding this study. The authors are grateful to Ms. S. Ben Sadoun, master student from Montpellier SupAgro, and to the technical staff from IAV Hassan II for their valuable support in acquiring the field data on faba bean. The contribution of CIAT and the University of Florida in acquiring and analyzing the data on bean is greatly acknowledged. 

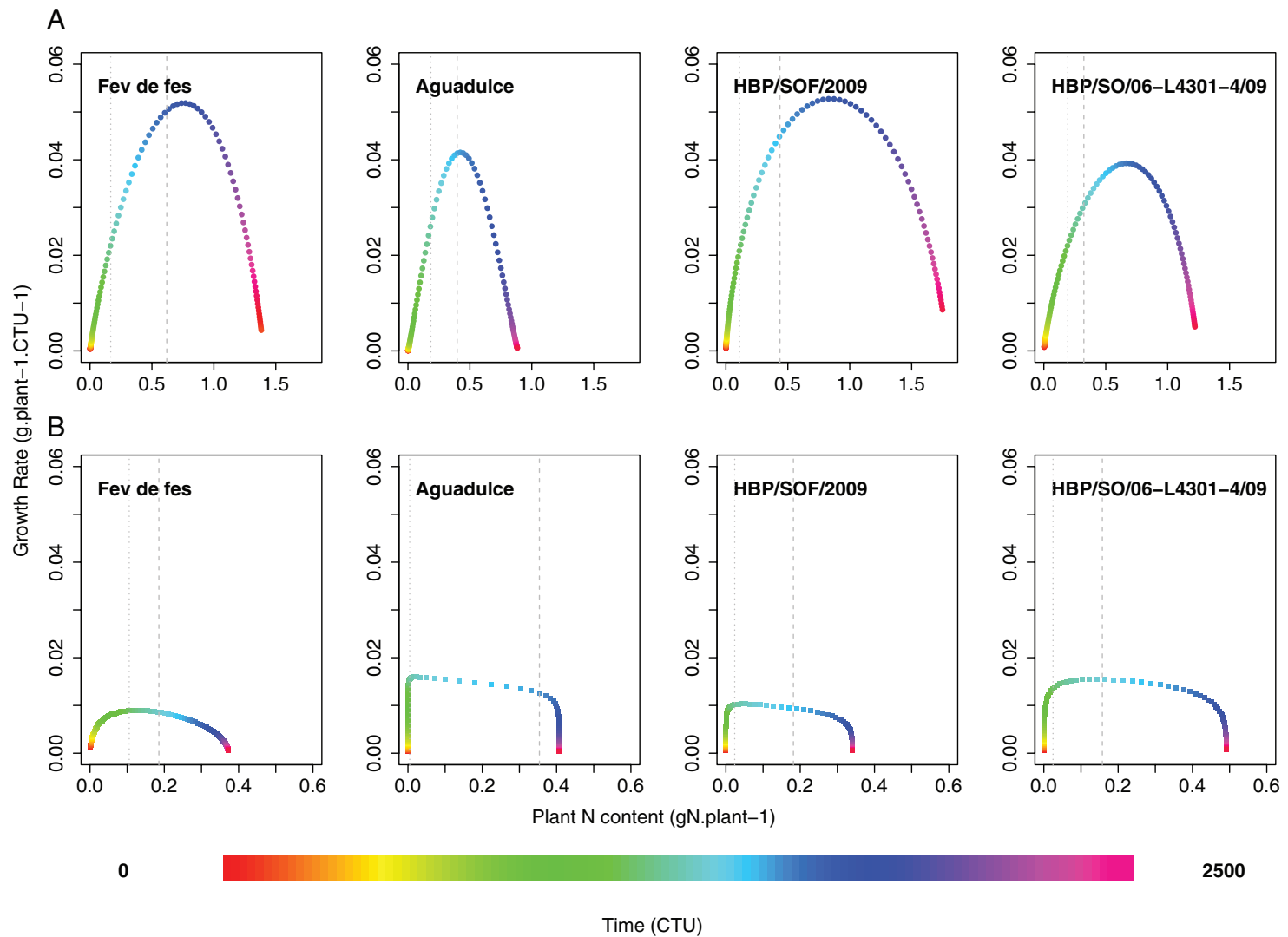

Fig. 7. GR vs $N$ accumulation rate (NAR) for faba bean for (A) irrigated and (B) non-irrigated conditions. These rates are based on the derivatives of the logistic models fitted to observed total dry weights and the total $N$ content. Point colors refer to time from sowing: The red-yellow points correspond to the beginning of cycle, while the blue-purple points correspond to the end of the cycle. The dotted vertical line is flowering time, while the dashed vertical line is the beginning of seed growth.

\section{References}

Amir J, Sinclair TR (1991) A model of water limitation on spring wheat growth and yield. Field Crops Res 28: 59-69

Bertheloot J, Wu Q, Cournède P-H, Andrieu B (2011) NEMA, a functional-structural model of nitrogen economy within wheat culms after flowering. II. Evaluation and sensitivity analysis. Ann Bot 108: 1097-1109

Boote KJ, Hoogenboom G (1998) Simulation of crop growth-CROPGRO model. In: Peart RM, Curry RB (eds) Agricultural Systems Modeling and Simulation. Gainesville, Florida, pp 651-692

Boote KJ, Mínguez MI, Sau F (2002) Adapting the CROPGRO legume model to simulate growth of Faba bean. Agron J 94: 743-756

Coleman JS, Mcconnaughay KDM, Bazzaz FA (1993) Elevated $\mathrm{CO}_{2}$ and plant nitrogen-use: is reduced tissue nitrogen concentration size-dependent? Oecologia 93: $195-200$

Cooper DR, Cottingham DGH, Ashton L (1976) Absorption and re-distribution of nitrogen during growth and development of field bean, Vicia faba. Physiol Plant 38: $313-318$

Devries JD, Bennett JM, Boote KJ, Albrecht SL, Maliro CE (1989) Nitrogen accumulation and partitioning by three grain legumes in response to soil water deficits 1 . Field Crops Res 22: 33-44

Dreccer MF, Grashoff C, Rabbinge R (1997) Source-sink ratio in barley (Hordeum vulgare L.) during grain filling: effects on senescence and grain protein concentration. Field Crops Res 49: 269-277

Godwin DC, Jones CA (1991) Nitrogen dynamics in soil-plant systems. In: Hanks J, Ritchie JT (eds) Modeling Plant and Soil Systems, Am Soc Agron, Madison, pp 287-321

Hammer GL, van Oosterom E, McLean G, Chapman SC, Broad I, Harland P, Muchow RC (2010) Adapting APSIM to model the physiology and genetics of complex adaptive traits in field crops. J Exp Bot 61: 2185-2202

Herdina, Silsbury JH (1990) Growth, nitrogen accumulation and partitioning, and $\mathrm{N}_{2}$ fixation in faba bean (Vicia faba cv. Fiord) and pea (Pisum sativum cv. Early dun). Field Crops Res 24: 173-188 
Hoffmann WA, Poorter H (2002) Avoiding bias in calculations of relative growth rate. Ann Bot 90: 37-42

Hunt R (2003) Growth analysis, individual plants. In: Thomas B, Murphy DJ, Mirray D (eds) Encyclopaedia of Applied Sciences. Academic Press, London, pp 588-596

Imsande J, Touraine B (1994) N demand and the regulation of nitrate uptake. Plant Physiol 105: 3-7

IPCC (2007) Climate Change 2007: Impacts, Adaptation and Vulnerability. Contribution of Working Groups I, II, and III to the Fourth Assessment Report of the Intergovernmental. Cambridge University Press, Cambridge, UK

Jamieson PD, Semenov MA (2000) Modelling nitrogen uptake and redistribution in wheat. Field Crops Res 68: 21-29

Lawlor DW (2002) Carbon and nitrogen assimilation in relation to yield: mechanisms are the key to understanding production systems. J Exp Bot 53: $773-787$

Lemaire G, Van Oosterom E, Sheehy J, He M, Massignam A, Rossato L (2007) Is crop N demand more closely related to dry matter accumulation or leaf area expansion during vegetative growth ? Field Crops Res 100: $91-106$

Maalouf F, Nachit M, Ghanem ME, Murari S (2015) Evaluation of faba bean breeding lines for spectral indices, yield traits and yield stability under diverse environments. Crop Pasture Sci 66: 1012-1023

Marrou H, Sinclair TR, Metral R (2014) Assessment of irrigation scenarios to improve performances of Lingot bean (Phaseolus vulgaris) in southwest France. Eur J Agron 59: 22-28

Martre P, Porter JR, Jamieson PD (2003) Modeling grain nitrogen accumulation and protein composition to understand the sink/source regulations of nitrogen remobilization for wheat. Plant Physiol 133: 1959-1967

Muchow RC, Robertson MJ, Pengelly BC (1993) Accumulation and partitioning of biomass and nitrogen by soybean, mungbean and cowpea under contrasting environmental conditions. Field Crops Res 33: 13-36

Ney B, Dore T, Sagan M (1997) Plant N \% in grain legume crops in relation to developmental stage. In: Lemaire G (ed) Diagnosis of the Nitrogen Status in Crops. Springer, Berlin Heidelberg, pp 108-110

Poorter H (1989) Plant growth analysis: towards a synthesis of the classical and the functional approach. J Exp Bot 75: $237-244$

Poorter H, Gamier E (1996) Plant growth analysis: an evaluation of experimental design and computational methods. J Exp Bot 47: 1343-1351

Quemada M, Gabriel JL (2016) Approaches for increasing nitrogen and water use efficiency simultaneously. Glob Food Sec 9: 29-35
Radford PJ (1967) Growth analysis formulae - their use and abuse. Crop Sci 7: 171-175

Rajcan I, Tollenaar M (1999) Source:sink ratio and leaf senescence in maize: II. Nitrogen metabolism during grain filling. Field Crops Res 60: 255-265

Ricaurte J, Clavijo Michelangeli JA, Sinclair TR, Rao IM, Beebe SE (2016) Sowing density effect on common bean leaf area development. Crop Sci 56: 1-9

Robertson MJ, Carberry PS, Huth NI, Turpin JE, Probert ME, Poulton PL, Bell M, Wright GC, Yeates SJ, Brinsmead RB (2002) Simulation of growth and development of diverse legume species in APSIM. Aust J Agric Res 53: 429-446

Ruiter JMD, Brooking IR (1996) Effect of sowing date and nitrogen on dry matter and nitrogen partitioning in malting barley. N Z J Crop Hortic Sci 24: 65-76

Siddique KHM, Regan KL, Tennant D, Thomson BD (2001) Water use and water use efficiency of cool season grain legumes in low rainfall Mediterranean-type environments. Eur J Agron 15: 267-280

Sinclair TR, de Wit CT (1975) Photosynthate and nitrogen requirements for seed production by various crops photosynthate and nitrogen requirements for seed production by various crops. Science 189: 565-567

Sinclair TR, Farias JR, Neumaier N, Nepomuceno AL (2003) Modeling nitrogen accumulation and use by soybean. Field Crops Res 81: 149-158

Sinclair TR, Muchow RC, Ludlow MM, Leach GJ, Lawn RJ, Foale MA (1987) Field and model analysis of the effect of water deficits on carbon and nitrogen accumulation by soybean, cowpea and black gram. Field Crops Res 17: $121-140$

Smith DL, Duak M, Hume DJ (1988) Effects of irrigation and fertilizer $\mathrm{N}$ on $\mathrm{N}$ accumulation and partitioning in white bean and soybean. Can J Plant Sci 68: 31-39

Soltani A, Sinclair TR (2012) Modeling Physiology of Crop Development, Growth and Yield. CABI, Wallingford, Oxfordshire, UK

Thomas RMJ, Fukai S, Peoples MB (2004) The effect of timing and severity of water deficit on growth, development, yield accumulation and nitrogen fixation of mungbean. Field Crops Res 86: 67-80

Tilman D, Cassman KG, Matson PA, Naylor R, Polasky S (2002) Agricultural sustainability and intensive production practices. Nature 418: 671-677

Voisin A-S, Gastal F (2015) Nutrition azotée et fonctionnement agrophysiologique spécifique des légumineuses. In: Schneider A, Huyghe C (eds) Les légumineuses pour des systèmes agricoles et alimentaires durables. Editions Quae, Versailles, pp 79-138

Voisin AS, Salon C, Munier-Jolain N, Ney B (2002) Effect of mineral nitrogen on nitrogen nutrition and biomass partitioning between the shoot and roots of pea (Pisum sativum L.) Plant and Soil 243: 251-262 


\section{Appendix 1 \\ Determination of tBSG and tTSG. Quality of estimations}

A non linear regression model was fitted between observed seed dry weight and time of observation in cumulated thermal unit (CTU) (Eqn A1).

$$
\text { DWseed }_{g, t}(\mathrm{CTU})=\frac{A_{\mathrm{DWS}, g, t}}{1+\mathrm{e}^{\left(-\frac{C T U-m_{\mathrm{DW} ., g, t}}{{ }_{\text {DDWs. }, t}}\right)}}
$$

where DWseed ${ }_{g, t}(C T U)$ is the seed dry weight for a genotype $\mathrm{g}$, in treatment or site $\mathrm{t}$, at CTU. $A_{\mathrm{DWw}, g, \mathrm{t}}$ $m_{\mathrm{DWw}, g, t}, s_{\mathrm{DWS}, g, t}$ are the parameters of the logistic function for each genotype and site. Parameter $m_{\mathrm{DWS}, g, t}$ represents the date (in CTU) when seed growth rate (SGR) is maximum and this date is noted as tSGRX. tBSG was calculated as the date, in CTU when DWseed $_{g, t, r}=0.05 \times A_{\text {DWs }, g, t}$ and tTSG as the date when DWseed $_{g, t, r}=0.95 \times A_{\text {DWs }, g, t}$. Eqn 2 was applied to each genotype and each treatment or site for both species.

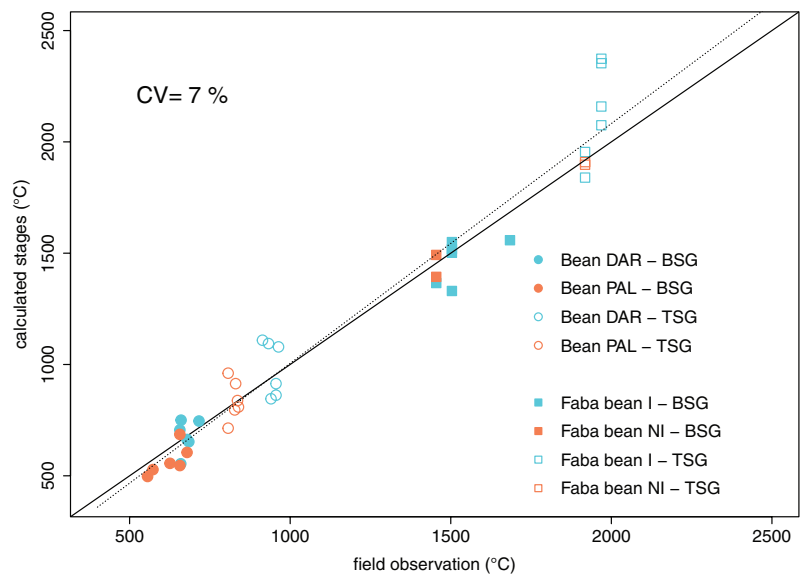

FIG A1. Estimated vs observed dates of BSG and TSG for bean in 2 PAL and DAR sites, as well as for faba bean in I and NI treatments. Solid line represents the graph bisector. Dotted line represents the prediction of linear regression between estimated and observed values. Coefficient of variation (CV) of the error of the estimation is equal to $7 \%$.

\section{Appendix 2 \\ Adjusted coefficients for dynamic of DW and NTOT}

Table A1. Adjusted coefficients for dynamic of DW and NTOT against CTU and for the dynamic of TGR as a function of NTOT. Max(NTOT) and max(TGR) are the coordinate of the curve maximum.

\begin{tabular}{|c|c|c|c|c|c|c|c|c|c|c|c|c|c|}
\hline \multirow[b]{2}{*}{ Faba bean } & \multicolumn{3}{|c|}{$D W=f(C T U)$} & \multicolumn{3}{|c|}{ NTOT=f(CTU) } & \multicolumn{7}{|c|}{$\mathrm{TGR}=\mathrm{f}(\mathrm{NTOT})$} \\
\hline & $A$ & m & s & $\mathrm{mN}$ & AN & $s N$ & A & An & s & E & $P$ & $\max (\mathrm{NTOT})$ & $\max (G R)$ \\
\hline Fev de fes & 47.11 & 1631.35 & 227.04 & 1597.65 & 1.40 & 207.43 & 47.1 & 1.40 & 227.04 & 1.16 & 0.91 & 0.757 & 0.052 \\
\hline Aguadulce & 28.09 & 1540.44 & 169.07 & 1558.94 & 0.89 & 190.19 & 28.1 & 0.89 & 169.07 & 0.90 & 1.12 & 0.423 & 0.042 \\
\hline HBP/SOF/2009 & 53.70 & 1708.08 & 254.46 & 1728.97 & 1.79 & 200.52 & 53.7 & 1.79 & 254.46 & 0.92 & 0.79 & 0.847 & 0.053 \\
\hline HBP/SO/06-L4301-4/09 & 41.75 & 1604.39 & 265.82 & 1567.50 & 1.24 & 227.42 & 41.7 & 1.24 & 265.82 & 1.15 & 0.86 & 0.670 & 0.039 \\
\hline Fev de fes & 11.26 & 1235.76 & 313.78 & 1368.49 & 0.37 & 199.13 & 11.3 & 0.37 & 313.78 & 0.66 & 0.63 & 0.127 & 0.009 \\
\hline Aguadulce & 14.25 & 1336.93 & 223.19 & 1470.89 & 0.41 & 45.99 & 14.3 & 0.41 & 223.19 & 0.55 & 0.21 & 0.021 & 0.016 \\
\hline HBP/SOF/2009 & 11.00 & 1330.24 & 266.38 & 1480.86 & 0.34 & 82.60 & 11.0 & 0.34 & 266.38 & 0.57 & 0.31 & 0.047 & 0.010 \\
\hline HBP/SO/06-L4301-4/09 & 16.03 & 1374.15 & 258.94 & 1465.97 & 0.49 & 96.18 & 16.0 & 0.49 & 258.94 & 0.70 & 0.37 & 0.137 & 0.015 \\
\hline \multicolumn{14}{|l|}{ Bean } \\
\hline CAL 96 & 14.76 & 529.83 & 105.57 & 483.85 & 0.42 & 128.76 & 14.8 & 0.42 & 105.57 & 1.55 & 1.22 & 0.246 & 0.035 \\
\hline Carioca & 18.28 & 634.45 & 101.70 & 573.43 & 0.50 & 134.13 & 18.3 & 0.50 & 101.70 & 1.82 & 1.32 & 0.307 & 0.045 \\
\hline DOR 364 & 16.77 & 585.41 & 78.74 & 534.32 & 0.49 & 158.14 & 16.8 & 0.49 & 78.74 & 1.91 & 2.01 & 0.287 & 0.053 \\
\hline G 21212 & 19.64 & 610.84 & 108.02 & 493.81 & 0.47 & 141.12 & 19.6 & 0.47 & 108.02 & 2.95 & 1.31 & 0.325 & 0.045 \\
\hline ICA Quimbaya & 19.60 & 587.76 & 102.28 & 493.93 & 0.47 & 143.86 & 19.6 & 0.47 & 102.28 & 2.50 & 1.41 & 0.308 & 0.048 \\
\hline SER 118 & 15.51 & 525.86 & 83.87 & 461.07 & 0.40 & 102.52 & 15.5 & 0.40 & 83.87 & 2.17 & 1.22 & 0.260 & 0.046 \\
\hline CAL 96 & 9.25 & 526.56 & 67.07 & 499.66 & 0.28 & 85.42 & 9.2 & 0.28 & 67.07 & 1.49 & 1.27 & 0.164 & 0.034 \\
\hline Carioca & 12.22 & 567.08 & 78.57 & 543.24 & 0.38 & 94.76 & 12.2 & 0.38 & 78.57 & 1.35 & 1.21 & 0.216 & 0.039 \\
\hline DOR 364 & 15.13 & 603.88 & 71.48 & 551.97 & 0.40 & 85.87 & 15.1 & 0.40 & 71.48 & 2.07 & 1.20 & 0.258 & 0.053 \\
\hline G 21212 & 13.26 & 579.94 & 75.33 & 541.18 & 0.42 & 95.10 & 13.3 & 0.42 & 75.33 & 1.67 & 1.26 & 0.250 & 0.044 \\
\hline ICA Quimbaya & 13.92 & 543.95 & 70.52 & 520.40 & 0.39 & 66.99 & 13.9 & 0.39 & 70.52 & 1.40 & 0.95 & 0.227 & 0.049 \\
\hline SER 118 & 15.28 & 635.82 & 85.82 & 569.53 & 0.36 & 84.11 & 15.3 & 0.36 & 85.82 & 2.16 & 0.98 & 0.249 & 0.045 \\
\hline
\end{tabular}

Edited by J. K. Schjørring 